\title{
ESCUELAS Y ENSEÑANZAS PRIMARIAS EN LA ESPAÑA MUSULMANA. NOTICIAS SOBRE EL REINO NAZARÍ Y LA ETAPA MORISCA (SIGLOS XIII-XIV)
}

Por

MANUEL ESPINAR MORENO

INTRODUCCION.

El tema de la enseñanza en la España islámica es hoy por hoy poco conocido a pesar de los trabajos que existen sobre esta cuestión. La tesis de Ribera lleva a la conclusión de que el Estado no influyó en la enseñanza tanto como en Oriente. La libertad de enseñanza que se produjo en $\mathrm{Al}$-Andalus estuvo practicamente garantizada y, todavia más, logró escapar incluso de los intentos de control de los alfaquíes, al menos hasta el siglo XIII, aunque no faltaron intentos argumentando razones teológicas. La enseñanza estuvo basada en su mayoría en las iniciativas individuales y sociales. Los particulares y, en especial, las personas de suficientes recursos imitaron las acciones de los más poderosos; en esta libertad de acción ve Ribera "el germen de todo el excepcional progreso de la cultura que ofrece el islam español, en contraste bien palpable con el islam oriental, donde el regimen intervencionista estorbó más que ayudó al desarrollo normal de la cultura científica".

Los trabajos sobre la enseñanza han estado orientados más al período altomedieval. Los siglos XI y XII, de transición y muy alborotados, no fueron favorables a un modelo único de enseñanza, en ellos comienzan a gestarse cambios sustanciales. Será a partir del XIII, con el reino nazarí, cuando asistimos de nuevo a un proceso donde la enseñanza tuvo unos planteamientos que nos atrevemos a calificar de "estatales" en cuanto que desde la corte se dieron las directrices necesarias que llevaron a que en el siglo XIV se planteara la enseñanza uniforme y obligatoria para todos los lugares. Las noticias y referencias del siglo XIII al XVI indican que las escuelas abundaron en las poblaciones granadinas 
tanto urbanas como rurales. Muchos de estos inmuebles se ubican junto a las mezquitas por lo que los alfaquíes y personas relacionadas con el culto tuvieron la responsabilidad de enseñar en todas las escalas del aprendizaje y la cultura. En contrapartida tenían asignadas las escuelas para pagar los maestros y hacer frente a los gastos ciertos bienes habices entre los que conocemos rentas de la tierra, hornos, casas, aljibes, tiendas, etc.

Las escuelas en el siglo XIV sirvieron para inculcar los principios religiosos y culturales. La enseñanza estaba muy ligada a lo religioso. Sin embargo, es un tema que hay que estudiar en profundidad. El concepto de comunidad musulmana nos lleva a ver como en la mezquita es donde se plasma el desarrollo individual y social del hombre. En ella se realiza el culto, la comunidad se desenvuelve allí. El hombre encuentra alivio a las necesidades espirituales y materiales. El niño desde los primeros años asiste a la escuela, aprende las primeras nociones y continua hasta lograr una formación superior en las madrazas.

El Islam como comunidad política, unidad de los creyentes, proyección social, contenidos mentales, mentalidades en general y personal tiene un proyecto de salvación comunitaria y a la vez personal. La mezquita es el lugar donde todos y cada uno se comunican con Dios; en torno a ella se desarrolla y amplía el espíritu, las letras y las artes, las enseñanzas filosóficas y teológicas, desde lo primario a lo más avanzado en el pensamiento, pero siempre de acuerdo a lo ortodoxo dentro de las escuelas musulmanas de interpretación del Corán, la Sunna y demás reglas establecidas por el común de los musulmanes.En la Suma de los principales mandamientos y devedamientos de la ley y çunna, se dice que las limosnas debían de utilizarse para conseguir cosas útiles y necesarias para la comunidad de los creyentes, entre ellas las escuelas y los maestros, sin olvidar el servicio del rey, de los alcaides,justicias, alfaquíes, almuédanos, mezquitas, puentes, pozos, rescate de cautivos, pobres, etc.

Por tanto, los mejores bienes eran los que se destinan y gastan en beneficio de la comunidad y cubren las neçesidades de 
los más necesitados. La financiación pues de las escuelas y otros servicios podian hacerse a través de los bienes habices, generales o particulares, es decir, los que al donarse tenían ya especificado un destino concreto o determinado o bien habían sido asignados por el monarca, sus representantes y alfaquíes para cubrir gastos de aquellas manifestaciones que se encaminan a la formación espiritual y material de los súbditos.

Entre las referencias de las fuentes encontramos datos sobre maestros, escuelas, capacidad de las mismas, medida de los inmuebles, bienes destinados a la enseñanza, lugares que tuvieron escuelas, etc.,que nos van a permitir acercarnos de manera cautelosa a uno de los temas más interesantes de la formación de los nin̄os en el islam granadino.Para ello tenemos que remontarnos a otras etapas anteriores pero siendo conscientes que todavia el tema está practicamente por investigar, a pesar de contar con trabajos de un profundo análisis,pero con muchas hipótesis que hay que constatar.

\section{LA ENSEÑANZA ELEMENTAL.}

Sobre la enseñanza elemental en los siglos XII al XV en $\mathrm{Al}$-Andalus y especialmente en el reino nazarí estamos poco informados. Los trabajos realizados hasta el momento son escasos y clásicos en su mayoría, aunque siguen siendo básicos en este tipo de estudios. Nos encontramos diferentes tramos: primaria,

\footnotetext{
${ }^{1}$ Sobre la enseñanza en la España musulmana tenemos varios trabajos, el más significativo, sin duda, es el de Julian RIBERA TARRAGO: La enseñanza entre los musulmanes españoles.Zaragoza,1893. Este mismo autor trabajó otras cuestiones de las que varias fueron recogidas en las págs. 229-359 de la obra Disertaciones y Ópúsculos, Madrid,1928.Obra que por su interés dice Levi- Provençal que debería ser remozada y especialmente las cuestiones de la enseñanza.En la Introducción a esta obra se alude a otros trabajos de RIBERA TARRAGO como son : Historia de las instituciones de enseñanza en los imperios musulmanes de Oriente (materiales recogidos por el autor), Origen del Colegio Nidamí de Bagdad, 1904; La enseñanza entre los musulmanes de España, 1895; Biblib́filos y bibliotecas en la España musulmana; La supresión de los exámenes; Los exámenes en China; etc.

Otros autores habían incidido en esta problemática pero especialmente dedicaron su esfuerzo al Islam Oriental, asi KREMER: Culturgeschichte des Orients, 1877; GUYAR: Civilisation musulmane, 1884; GOLDZIHER: Muhanmedanische Studien, 1890; MARÇAIS; Taqrib de en-Nawawi, 1902 (traducción); J. ZEIDAN: Historia de la civilización islámica o Tarij altamadon alislami, 1904; G. SARTON: Introduction to the History of Science, Baltimore, 1927; QUATREMERE: Le goût des livres
} 
secundaria y superior, las dos últimas se confunden a menudo y dependía del maestro y de las enseñanzas impartidas.

En el siglo pasado realizó J.Ribera un trabajo sobre la enseñanza en la España musulmana donde analiza sus diversos grados, es una auténtica monografía basada según Levi-Provençal ${ }^{1}$ en un despojo casi sistemático de repertorios biográficos, entre sus páginas encontramos datos útiles y de primera mano, pero apenas nos ofrece algunas referencias a los edificios, medidas y otras cuestiones relacionadas directamente con la enseñanza elemental.

Tanto Ribera como Levi-Povençal, H.Pèrés y Rachel Arié llaman la atención sobre la asistencia a la escuela y dicen que a ella iban los hijos de familias acomodadas y con recursos, mientras que los de ínfima categoría social y vida pobre o miserable no era habitual que asistieran a las escuelas. Otro dato a tener en cuenta es que los habitantes de las ciudades y núcleos urbanos importantes solían tener más facilidades que en el campo para iniciar su aprendizaje. La vida en la ciudad exige mayor preparación y la familia es consciente de ello, "el padre de familia que vivía en la ciudad tenía empeño en que sus hijos, varones o hembras, recibieran desde la más tierna infancia una instrucción elemental" 2 .

La posibilidad de alcanzar puestos importantes invitó a campesinos y hombres de la ciudad a cursar estudios. No existían títulos aunque si las llamadas licencias (iyaza) para enseñar, especie de diploma, pero la fama de buen maestro se lograba en las reuniones literarias y en la enseñanza impartida a los alumnos siempre ávidos de aprender.

chez les oricntaux, 1838 y Mélanges d'histoire et de philologie orientale, París, 1857, pp. 1-39. Más recientes son los trabajos de E. LEVI-PROVENÇAL:" La España musuimana hasta la caida del Califato de Córdoba (711-1031 de J. C.). Instituciones y vida social e intelectual". Tomo $V$ de la Historia de España dirigida por R. MENENDEZ PIDAL, Espasa-Calpe, S.A., Madrid, 1957 y traducida por E. GARCIA GOMEZ. Cf. especiaimente capitulo VII sobre la vida privada. H. PERES: Esplendor de al-Andalus. La poesía andaluza en árabe clásico en el siglo XI. Sus aspectos generales, sus principales temas y su valor documental. Madrid, 1983 y $\mathrm{R}$ ARIE: L'Espagne musulmane au temps des Nastides (1232-1492). Paris, 1990, especialmente capítulo VII.

${ }^{1}$ E. LEVI-PROVENÇAL:" España musulmana hasta la caída del Califato ...", Ob. cit., pp 257 292 y especialmente p. 263 y ss.

$2_{\text {bidem }}$ 
Mientras que la enseñanza no contó con el apoyo del estado o de la religión musulmana fueron los padres los encargados de financiar el gasto de los maestros y de los niños. En ocasiones los maestros recibían pensiones del gobernador o del príncipe, en dinero o en especie, pero poco importantes', nos dice Ribera que lo más frecuente era la ausencia de retribución o regulación por el estado ${ }^{2}$.Se perdió la retribución de los que se ocupaban de enseñar a los niños pobres ${ }^{3}$, cosa que ya había ocurrido en la etapa califal. Sin embargo, en el siglo XIV de nuevo la enseñanza gratuita tiene su más importante manifestación según el Código de Yusuf I. Lo más corriente si se disponía de medios económicos era ajustar un preceptor que iba a la casa o bien tenía una pequeña escuela o local donde los niños se trasladaban. Estas escuelas se denominaban maktab o kuttaba ${ }^{4}$ y dentro de las ciudades predominaron en los barrios donde vivían las familias más adineradas. En la vida de las ciudades musulmanas estos "colegios" o "escuelas", muy rudimentarias en opinión de Levi-Provençal estaban sometidas en teoría a la vigilancia del almotacen de la ciudad que daba cuenta del funcionamiento a las autoridades superiores.

El maestro se denominaba mu addib o mu allim y reunía para desempeñar su labor,casi diaria,un número pequeño de alumnos.Estos acudían a desarrollar sus tareas de aprendizaje a edificios pequeños o habitaciones que muchas veces eran pequeñas tiendas o almacerías (masriyya) con salida directa a la calle. La enseñanza de estos pequeños grupos reportaba un salario con el que el profesor solía vivir o al menos le permitía hacer frente a

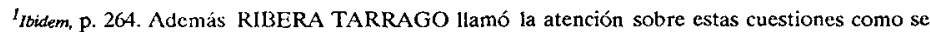
puede ver en Disertaciones y Opúsculos, sobre todo en la Introducción a esta obra.

${ }^{2}$ lbidem.

${ }^{3}$ RIBERA TARRAGO en Disertaciones y Opúsculos y especialmente en la Introducción.

${ }_{4}$ Ibidem, además R ARIE: L'Espagne musulmane ..., p. 423 y Encyclopédie de l'Islam, por B. Lewis, Ch. Pellat y J. Schacht. París, 1965. Cf. las acepciones Tadris, Djam'a, Ma'arif, Madraza, Kuttaba, etc.
} 
una serie de gastos de su vida diaria si lo compaginaba con otros ingresos que obtenía de trabajos complementarios a la enseñanza.

La enseñanza elemental consistía en enseñar el Coran y el aprendizaje de los primeros elementos gramaticales.Los programas de enseñanza y el desarrollo de los estudios estaban encaminados a conseguir un progreso,estas enseñanzas respetaban unos principios fijados por la tradición y los maestros se comprometían a respetarlos y mantenerlos,esta tradición y respeto hacia ella se denominaba shart.

El salario que entregaba el padre del alumno al preceptor o maestro tanto si este se desplazaba a la vivienda del alumno como si era el niño el que iba a la escuela o a casa del maestro era generalmente abonado anualmente.Lo más usual era confeccionar y redactar un contrato donde se especificaba el sueldo,condiciones,tiempo,metas a alcanzar,etc.,algunos de estos contratos han llegado hasta nosotros gracias a los formularios de los juristas musulmanes ${ }^{1}$.Se alude en estos documentos a la entrega de dinero mensual o en tiempos más largos como el trimestre o semestre,al pago en alimentos sobre todo productos como el aceite de oliva,harina,etc.,y es curioso comprobar como se fue imponiendo la costumbre de gratificar al maestro cuando se celebraban fiestas, especialmente las dos grandes fiestas coránicas,cuando el alumno aprendía a escribir,cuando terminaba de aprenderse el Coran de memoria,etc. Aunque no conocemos la mención de maestras si que nos dice Ibn al-Faradi que en las mansiones acomodadas se ajustaban mujeres que cumplían estos requisitos en condiciones análogas a los hombres.La enseñanza de la mujer estuvo garantizada en Ia España musulmana y abundaron las poetisas en todos los tiempos, algunas adquirieron fama internacional.

El número de alumnos fue reglamentado en el mundo islámico,como nos dice Ibn Abdun, para lograr unos resultados satisfactorios y poder desempeñar una labor cuidada en el arte de

'E. LEVI-PROVENÇAL: La España musulmana ..., p. 264, cita los formularios de al-Qaisi, fols. 100-101 y de al-Chaziri, fol. 59r, ya utiizados por RIBERA en su excelente estudio. 
enseñar,así en el siglo XII nos dice:

"Los maestros no deben tener demasiados niños.Se les prohibirá que los tengan;pero yo digo que no harán caso,porque nunca se pone uno al servicio del común,sobre todo para la enseñanza ,ni enseña nada como hace falta.La enseñanza, èn efecto, es un arte que requiere saber las cosas y tener práctica y paciencia de inculcarlas. Es como la doma de un potro reaccio,al que hay que tratar con habilidad,gracia y cariño, hasta que se domestica y acepta ser dirigido. Ahora bien: la mayoría de los maestros son unos ignorantes en el arte de enseñar, porque saberse de memoria el Alcorán es una cosa, y el enseñar es otra cosa muy distinta, que solo domina a la perfección èl que de veras la sabe. Enseñar debe consistir en hacer que el alumno aprenda a recitar el Alcorán con una dicción armoniosa, a tener una bella escritura y a descomponer una palabra en sílabas, y si el alumno es ya mayor, a hacer que rece como es debido, escribiéndoles la profesión de fe y lo que ha de decirse en la oración. A los maestros de escuela incumbe proporcionar a los alumnos... una bella letra, una buena dicción, una hermosa recitación del texto alcoránico y el conocimiento de las pausas y acentos al recitar. Nada hay en eí mundo más útil que este último conocimiento para el que escribe y lee, y que el del cálculo para el que compra y vende"1.

Como se desprende por tanto de este pasaje de Ibn Abdun la condición esencial del maestro radica en el modo de saber enseñar e inculcar y esto se consigue sobre todo con la práctica y buenas maneras. Entre sus funciones encontramos que debe de tratar al alumno "con habilidad,gracia y cariño".Sin embargo,la opinión sobre la profesión es bastante negativa y acusa a los maestros de ignorantes. Llama la atención sobre la enseñanza memorística y acaba su discurso diciendonos en qué debe consitir la enseñanza y las fases o estadíos de la misma persiguiendo una serie de fines que había que conseguir : aprender a recitar con dicción armoniosa el Libro Sagrado,lograr una bella escritura lo que suponía ejercitar la caligrafía,descomponer las palabras,lograr que el alumno mayor supiera rezar para ello escribiría la profesión de fe y otras oraciones para cuando asistiera a la mezquita. No podemos olvidar que el musulmán tiene que orar cinco veces al día y que asistía casi diariamente a la mezquita para cumplir con sus mandamientos religiosos. En difinitiva, la enseñanza estaba encaminada a lograr una buena formación en letras y en ciencias,

${ }^{1}$ E. GARCIA GOMEZ y E. LEVI-PROVENÇAL: Sevilla a comienzos del siglo XII. El tratado de Ibn 'Abdun. Madrid, 1948 y Sevilla, 1981. Traducción de este pasaje pp. 91-92. 
una destinada al conocimiento de lo religioso,al conocimiento del mundo que rodea al hombre y en el que se desenvuelve,conocer el pensamiento y las corrientes de opinión,etc, y la otra a las matemáticas y al cálculo para saber comprar y vender.Eran enseñanzas complementarias destinadas a suplir y colmar las necesidades espirituales y materiales de los niños y en fin de los futuros hombres y mujeres del mundo islámico.

Las cualidades del maestro es otra de las cuestiones estudiadas y recogidas por Ibn Abdun,en sus palabras encontramos una opinión generalizada en su tiempo que nos traduce el modo de pensar de sus contemporáneos sobre la profesión docente.Si eran los padres los que financiaban la enseñanza o era el estado el maestro no debía de faltar a sus tareas en la escuela,todavia peor si los gastos corrían a cargo de las limosnas o dineros de los creyentes destinados por estos en beneficio de la comunidad.Entre las faltas cometidas por los docentes se encuentran las numerosas ausencias porque destinaban aquel tiempo a asistir a comidas sociales,entierros de amigos y conocidos,realizar declaraciones en el juzgado,etc., y otras muchas excusas que les permitían dejar la escuela y no cumplir con sus obligaciones.Había que evitar tales estafas y para ello se debían tomar las medidas oportunas por parte de las autoridades:

"Hay que prohibir a los maestros de escuela que asistan a festines de ceremonia, entierros y declaraciones en el juzgado, salvo en día de vacación, puesto que son asalariados y hacen perder su dinero a las gentes ignorantes y sin juicio que los pagan[para educar a sus hijos]"1.

Los alumnos se quedaban solos y el maestro se dedicaba a otras ocupaciones, en el siglo XII se hicieron observaciones llenas de indignación como las que nos recuerda Ibn Abdun para Sevilla pero que no serían muy distintas en otras tierras musulmanas.

La profesión del maestro debía ser ejercitada por personas capacitadas,de una edad determinada y con unas cualidades

${ }^{I}$ loidem, p. 91. 
religiosas y buenas costumbres,se destaca su prudencia y habilidad en el trato con las gentes y en su vida diaria entre sus convecinos.La labor a desarrollar exigía vocación,preparación y entrega a la comunidad pues,no en vano, tenían en sus manos la responsabilidad de la formación de los futuros hombres de la comunidad musulmana, de ellos saldrían los alfaquíes, hombres del ejército,maestros,profesores y buenos ciudadanos dedicados a las tareas agrícolas, industriales, ganaderos, comerciantes,etc., que iban a hacer que las ciudades y los demás núcleos habitados del mundo musulman fueran una sociedad rica y dinámica'.

Se alaba la constancia y preocupación por el discente.Las autoridades tenían la obligación cívica y moral de evitar las faltas de los maestros poniendo en práctica determinados recursos a su alcance según las leyes, el juez y el cadí pueden interrogarlos sobre los métodos y manera de enseñar, debían prohibir que utilizaran su puesto en la sociedad para sobresalir y destacar entre sus conciudadanos, obtener cargos y remuneraciones indebidas. Se dice que no tenían que recibir regalos o ser nombrados depositarios de ciertos fondos sociales o religiosos.Sin embargo,la opinión de los autores y escritores del período también nos hablan del buen maestro,el que era callado,honrado,sin medios económicos,trabajador,preocupado por los alumnos y por la enseñanza, y especialmente por el aprendizaje, debía de ser aceptado por la comunidad y sobre todo premiado por las autoridades.El propio Ibn Abdun nos dice:

"El maestro de escuela no ha de ser ni soltero ni mozo, sino hombre de edad, honrado, religioso, de buenas costumbres, piadoso, de pocas palabras y nada amigo de escuchar lo que no le concierne. No ha de asistir a entierros lejanos, ni tomarse muchas vacaciones, ni abandonar a los niños, ni dejarlos solos más que para ir a comer o a hacer sus abluciones. Debe estar fijo en su puesto y tener cuidado de las cosas de sus alumnos.Si el juez secundario y el cadí advierten que un maestro de escuela va con frecuencia a sus curias para prestar testimonio, deben interrogarle sobre cómo ejerce la enseñanza, y, si tiene una escuela

\footnotetext{
'L. TORRES BALBAS: Ciudades hispanomusulmanas, Madrid, 1971; A. GARCIA BELLIDO y otros: Resumen histórico del urbanismo en España, Madrid, 1968; J. ABELLAN PEREZ:" Del urbanismo musulmán al urbanismo cristiano. I. Andalucía Occidental". Simposium Internacional sobre la ciudad islámica. Zaragoza, 1988; y M. ESPINAR MORENO:" Del urbanismo musulmán al urbanismo cristiano. II. Andalucía Oriental". Simposium Internacional sobre la ciudad islámica. Zaragoza, 1988 (En prensa).
} 
alcoránica, no aceptarán su testimonio, porque lo único que quiere es figurar y adornarse con el título de testigo notario, para recibir regalos y que se le confien depósitos, y para hacerse pasar por persona conocida y adquirir reputación de hombre de bien,cuando está muy lejos de ambas cosas; si, por el contrario, no tiene escuela, es de honradez conocida y el cadi ha oido hablar bien de él, que lo acepte. Yo he conocido a un buen número del tipo que he descrito, ipobres desgraciados!"1 .

El comportamiento de los alumnos tampoco es olvidado y se llama la atención sobre el cómo corregirlos "es como la doma de un potro reaccio, al que hay que tratar con habilidad, gracia y cariño, hasta que se domestica y acepta ser dirigido "2 .Los castigos deben evitarse en lo posible pero Ibn Abdun nos recuerda que si este es necesario no hay porque no cumplirlo, se aplicará de manera racional y de acuerdo a la edad y fuerza física del alumno:

"No deberá castigarse a un niño con más de cinco azotes, si es mayor, y de tres si es pequeño, dados con un rigor proporcionado a su fuerza física ${ }^{33}$.

El material utilizado por los alumnos era practicamente igual que el utilizado hasta hace poco en las escuelas alcoránicas del Norte de Africa, especialmente Marruecos. Cita Levi-Provençal que entre los materiales estaban las tabletas de madera, cálamos de caña, tinta de lana quemada, alguno de estos materiales tenían poca resistencia e incluso mala calidad, a lo largo del tiempo se reglamentó su fabricación para evitar fraudes, así "no debe fabricarse pergamino que no sea raspado, y no ha de hacerse con pieles de cordero flaco".4. García Gómez y Levi-Provençal insertan en su obra una nota explicando que la raspadura del pergamino tenía lugar tanto con el nuevo, que se raspaba antes de venderlo, como con el viejo, ya escrito anteriormente, y utilizados varias veces (palimpsestos) de los que conocemos ejemplos en el período califal. Los muebles de escritorio, alacenas, cerraduras, aros de

\footnotetext{
${ }^{1}$ L. GARCIA GOMYZ y E. LEVI-PROVENÇAL: Sevilla a comienzos ..., pp. 92-93. 
hierro, tijeras, etc. deben de confeccionarse con una calidad aceptable, pues se alude a que las tablas de las alacenas y los cofres no estaban clavadas ni ensambladas y las llaves de dos dientes "son sumamente fáciles de abrir y debe suprimirse la fabricación". Se fabricarían de madera de buena calidad y dureza ${ }^{1}$. Un pasaje del Rawd al-Qirtas nos especifica y permite ver el uso de las tablillas y los cuadernos donde se anotan los pasajes del Corán,realizan comentarios,etc.,el pasaje de esta fuente nos dice:

"El Príncipe de los Creyentes al-Said llegó a Mequínez; y sus habitantes salieron a pedirle perdón, precedidos por el santo jeque Abu Alí Mansur ben Azuz y los niños de las escuelas con las tablillas sobre la cabeza y los cuadernosdel Alcorán- en las manos.Los perdonó y se dirigió a Fez, en cuyos alrededores acampó por la parte sur."2.

Otro testimonio, de 1210-1212, nos muestra al emir Abu Yusuf Yaqub ben Abd al-Haqq preocupado por los pobres y los débiles. Se especifica en el Rawd al-Qirtas que cuando llegó al poder hizo hospitales para los enfermos y locos, les asignó rentas y lo que necesitaban de comida y bebida, los médicos cuidarían todo el día de ellos cobrando dinero del tesoro. Esto mismo hizo con los paralíticos, ciegos y faquires, asignándoles dinero del tributo pagado por los judíos. Sin embargo, no olvidó la enseñanza y nos dice el cronista: "...construyó escuelas y pensionó en ellas a estudiantes para leer el Alcorán y aprender las ciencias, señalándoles su pensión mensual, por su deseo del premio de Dios. El le haya pagado su buena intención"'s

Este testimonio es de 1242 pero se citan ya antes, en el siglo XI, escritorios, cortaplumas, cálamos y otros materiales de

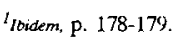

${ }^{2}$ IBN ABI ZAR: Rawd al-Qirtas. Traducido y anotado por A. Huici Miranda. Valencia, 1964. 2 vols., p. 498. En esta misma fuente encontramos referencias a que en 1211-1212 uno de los jeques santones, Abu 'Abd Allah ben Hariz, conocido como Ibn Tahmist de Fez, tenía una hermosa escritura y escribía Coranes que luego entregaba a los que consideraba dignos, fue un hombre dado al estudio y a las ciencias, p. 522 .

${ }^{3}$ lididem, pp. 566-567.
} 
escritura ${ }^{1}$.

Los niños que asistían a la escuela desarrollaban su labor sobre todo de forma memorística, repetitiva, machacona,que se oía desde la calle o las casas próximas a la escuela como todavía ocurre en $\mathrm{Fez}$ y otros lugares del mundo islámico. Esta "melopea gangosa"2 repitiendo el texto sagrado y otras nociones se grababan en la memoria del alumno y en caso de dejadez o falta de interés recibía un castigo corporal aplicado por el maestro delante de los otros niños para que sirviera de ejemplo. Además del aprendizaje del Corán se les iniciaba en el conocimiento de las reglas elementales de morfología y sintaxis a través de manuales elementales.

Tras su asistencia a la escuela y la llegada a la adolescencia los alumnos continuaban bien hacia estudios superiores que se impartían en las mezquitas aljamas de las ciudades o abandonaban los estudios para trabajar de aprendiz de un oficio o en el campo.Si continuaban estudiando abarcaban las enseñanzas del fiqh malikí en al-Andalus,literatura y otras materias.

Los métodos pedagógicos tampoco son muy conocidos aunque Ibn Jaldun nos ilustra sobre ellos en su Muqaddima, dice que antes de su tiempo, siglo XIV, se empleaban en al-Andalus y el occidente musulmán unas enseñanzas peculiares, se apoya en un pasaje de Ibn Arabí de Murcia donde expone que a partir del siglo $\mathrm{XI}$, en el período de los reinos de taifas, se impuso en al-Andalus un sistema distinto al que utilizaron en el Magreb y en el mundo oriental. El estudio del Corán estaba precedido por el de la lengua y la poesía, se perseguía que el alumno tuviera unos conocimientos filológicos y un modelo de dicción que le facilitara la profundización y conocimiento del Libro Sagrado.

Sobre esta cuestión el propio Levi-Provençal escribe "Es

\footnotetext{
${ }^{1}$ H. PERES: Esplendor de al-Andalus.., p. 437.

${ }^{2}$ E. LEVI-PROVENÇAL: La España musulmana ..., ob.cit.
} 
posible que esta indicación de Ibn Jaldun fuera exacta, aunque no disponemos sobre el asunto de ningún documento contemporáneo lo bastante explícito.De todos modos, parece hallarse en cierta contradicción con la de otro autor de relieve, el gran Ibn Hazm, quién así mismo trata la cuestión de los métodos pedagógicos en una obrilla, todavia inédita, titulada Maratib al-ulum o Clasificación de las Ciencias "'.

En esta obra defiende que el Coran sea estudiado antes que ninguna otra materia; el niño una vez que aprende a leer y escribir, con cinco años aproximadamente, y conociendo el texto sagrado pasará a los estudios filológicos y a la poesía para continuar hacia estudios superiores, donde se perseguía la especialización de los estudiantes en los campos de la ciencia, sin olvidar que la enseñanza islámica de este tiempo estaba basada en los estudios jurídicos o en los literarios, así nos recuerda al-Qaisi que el maestro de escuela enseñaría gramatica, bellas letras y poesía exceptuando la báquica y la satírica ${ }^{2}$.

En conclusión, nos encontramos con dos opiniones contrapuestas respecto a los métodos pedagógicos y al sistema de enseñanza.Las materias y obras estudiadas en el siglo XI han sido analizadas por H.Pèrés ${ }^{3}$ y por Rachel Arié para el período nazarí .Entre los estudios y obras encontramos comentarios, biografías, antologías, ciencia y medicina, hípica, historia, relaciones de viajes, obras en prosa y poesía, etc., que hizo llegar su fama a otras tierras musulmanas de Africa del Norte y Oriente, en contrapartida nos encontramos la venida de ciertas obras, modas

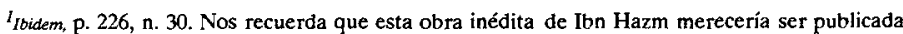
y traducida en su totalidad por contener puntos de vista muy interesantes, aunque con una visión muy particular de su autor. Recoge obras y opiniones del siglo XI. Además, su importancia es todavía mayor si se tiene en cuenta que por el momento sólo existe un texto en Estambul, del que M. ASIN PALACIOS nos proporciona un análisis en su trabajo "Un códice inexplorado del cordobés Ibn Hazm", Al-Andalus, 2 (1934), pp. 46-56.

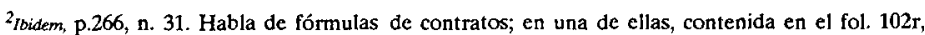
es donde se estipulan las materias que el maestro debía enscñar.

${ }^{3}$ H. PERES: Esplendor de al-Andalus ..., pp. 37-48.

${ }^{4} \mathrm{R}$. ARIE: L'Espagne musulmane ..., pp. 427 y ss.
} 
y personajes que impartieron su enseñanza en al-Andalus.

H.Pèrés analiza el pasaje de Ibn Jaldun donde se expone como Ibn Arabi propuso a los orientales en el relato de sus viajes un plan de enseñanza original, consistía en "seguir el sistema de los españoles y enseñar el árabe y la poesía antes que las otras ciencias"1 .Las palabras transmitidas por Ibn Jaldun son estas:

"Como los poemas eran, para los antiguos árabes, registros [en los cuales incluían todo lo que les parecía importantel, haría falta comenzar por el estudio de la poesía y su lengua; la corrupción [gradual] del lenguaje [que se habla] lo exige imperiosamente. El alumno pasaría a continuación al estudio del cálculo... Después se pondría a leer el Corán, del que encontraría fácil el estudio gracias a estos trabajos preliminares"

H. Pèrés añade que parece que los andaluces pusieron en práctica los consejos de Abu al-Hamid donde recomienda la búsqueda del conocimiento de todos los géneros literarios, los que trataran de hacerse sabios en la ciencias religiosas, especialmente en el Coran y en las prescripciones de la Ley divina, cultivo de las lenguas árabes para hablar correctamente, conseguir una hermosa escritura para engalanar los escritos, aprender de memoria poemas, familiarizarse con ideas rebuscadas y expresiones insólitas, leer historias de los árabes, retener en la memoria los grandes hechos,etc, que finaliza diciendonos que les serían muy útiles cuando tratasen de medrar.

En España las ciencias secundarias o especulativas tuvieron una gran importancia,más que en la religión se pensó en el hombre y la educación tiende al desarrollo armónico de las facultades humanas, consecuencia lógica del místicismo y del humanismo. La enseñanza en al-Andalus dió cabida desde la más temprana edad "a las humanidades" impartidas en todas partes.

La enseñanza musulmana en al-Andalus y especialmente

\footnotetext{
'H. PERES: Esplendor de al-Andalus ..., p. 32.

${ }^{2}$ tbidem, p. 32.
} 
en el reino granadino,siglos XIII-XV, siguió la escuela malikí aunque se conocen citas y personajes sobre otras escuelas como la sií, hambalí y zahirí, pero sólo las profesaron raros adeptos y siempre estuvieron expuestos a la hostilidad implacable de los malikíes'.

De esta manera la escuela malikí impuso unas enseñanzas y sus maestros y hombres de religión influyeron en el desarrollo del pensamiento en al-Andalus. La Mudawwana de Malik fue la obra de mayor peso entre los intelectuales y sus discípulos, los juristas granadinos tuvieron fama y entre ellos se citan personalidades y maestros de un gran prestigio ${ }^{2}$.

Los centros dedicados a la enseñanza que aparecen citados en las crónicas y diccionarios biográficos estaban sobre todo en las grandes aglomeraciones urbanas: Granada,Almería,Málaga,Guadix y sus alrededores. La opinión de R.Arié ${ }^{3}$ es que el sistema de enseñanza impartido en estas ciudades merecería ser estudiado aunque la documentación es escasa. Los estudios superiores se impartían en La Alhambra donde los monarcas llevaban para la educación e instrucción de sus hijos a los maestros de mejor fama y preparación ${ }^{4}$.Algunos de estos profesores, desde el siglo XII, se dedicaron a la formación de los estudiantes en las mezquitas, zawiyas y rábitas. La pasión por los estudios fue grande entre los granadinos de todas las clases sociales, la enseñanza conoció con los nazaríes momentos de esplendor y el estado llegó a financiar estudios, desarrolló ayudas a los estudiantes y con Yusuf I se ordena que la escuela sea gratuita por lo que obliga a que existan colegios de enseñanza primaria en casi todos los lugares del reino que reunan una condiciones míminas:

\footnotetext{
${ }^{1}$ E. LEVI-PROVENCAL: La España musulmana ..., ob. cit., cf. cápitulo "La vida religiosa e intelectual", pp. 293-330. Y para el período que nos ocupa R. ARIE, L'Espagne musulmane ..., ob. cit., capítulo " $\mathrm{La}$ vie religieuse e intellectuelle, réssor artistique", pp. 417-473, analizando en profundidad el malikismo granadino.
}

${ }^{2}$ R. ARIE: L'Espagne musulmane ..., p. 420

${ }^{3}$ bidem, p. 423.

4 Ibidem, p. 424. 
"Todos los pueblos del reino estableceran escuelas gratuitas y uniformes en sus enseñanzas"

Además, sabemos que muchas familias hicieron enormes esfuerzos financieros para hacer frente a las necesidades de los estudios. La profesora R.Arié cita un testimonio de Ibn Said donde nos encontramos que en Egipto ya en el siglo XIII los estudiantes percibían una ayuda ( giraya), especie de beca, que les permitía dedicarse al estudio con cierta quietud y sosiego ${ }^{2}$.

La enseñanza superior en Granada tuvo un gran impulso con la fundación de la Madraza en tiempos de Yusuf I. No conocemos en el siglo XIII ningún centro de este tipo aunque si en Málaga como ha puesto de manifiesto María Jesus Rubiera ${ }^{3}$ adelantandose en esto a la capital nazarí. Sin embargo, la enseñanza superior es más conocida que la elemental pero no es objeto de estudio en este trabajo ${ }^{4}$.

\section{LAS ESCUELAS GRANADINAS.}

Nos dicen los estudiosos de la enseñanza musulmana que las escuelas estaban la mayoría de las veces ligadas a las mezquitas,zawiyas y rábitas,donde se enseñaba a los niños las primeras letras y existía en ellas una ordenación del sistema docente.En las mezquitas mayores o aljamas se tenían las escuelas superiores y las madrazas,centros donde se estudiaban materias

\footnotetext{
${ }^{1}$ C. SANCHEZ ALBORNOZ: La España musulmana según los autores islamitas y cristianos medievales. Madrid, Espasa-Calpe, S.A., Madrid, 1982. Tomo II, pp. 510-512.

${ }^{2} \mathrm{R}$. ARIE: L'Espagne musulmane ..., p.425.

${ }^{3}$ María Jesús RUBIERA MATA: "Datos sobre una madraza en Málaga anterior a la nasri đe Granada", Al-Andalus 35(1970), pp. 223-226. Y R ARIE: L'Espagne musulmane, ... ob. cit., pp. 425427 , donde cita noticias sobre la madraza granadina y bibliografía.

Ibidem. Existe una amplia bibliografía sobre la enseñanza superior en el mundo islámico, pero sobre la enseñanza elemental y la secundaria apenas se ha trabajado.
} 
muy específicas ${ }^{1}$ de las que poseemos pocas noticias ${ }^{2}$. Por el contrario los estudios secundarios y primarios,en el período que nos ocupa,se desarrollaban en las mezquitas secundarias o de barrio.En la ciudad de Sevilla,en el siglo XII, nos llaman la atención E.García Gómez y E.Levi-Provençal que Ibn Abdun en su Tratado especifica estos hechos y nos lo comentan así:

"Después de acabar con la mezquita mayor,Ibn Abdun pasa a ocuparse de las mezquitas secundarias, que le interesan sobre todo en cuanto son, al mismo tiempo que lugares de culto, las escuelas en que los niños aprenden el Alcorán y reciben su instrucción primaria. Con este motivo dirige acerbas críticas a los maestros de escuela que, en su opinión, carecen de conciencia profesional, son a menudo ignorantes y aprovechan la menor ocasión -ser llamados a declarar, o asistir a comidas nupciales o a entierros- para abandonar a sus alumnos y dejarlos solos. Para evitarlo, llama la atención del cadí, que debe obligarlos a tener una concepción más estricta y honrada de su papel de educadores" ${ }^{* 3}$.

No en vano encontramos en el Tratado de Ibn Abdun las nociones básicas de la sociedad y los problemas suscitados en las sociedades musulmanas,toda sociedad tenía que estar dirigida por un buen gobierno. Cuando nos habla del príncipe y de sus gobernantes nos recuerda que éste tiene un papel director en la sociedad,es respecto a la nación lo que la inteligencia para el hombre "que si es correcta le procura la comprensión y unos juicios bellos y ponderados" ${ }^{\prime \prime}$. La nación depende de él y ésta marchará bien si reune cualidades o por el contrario se impondra el caos y la decadencia si tiene defectos y se hace partícipe del mal gobierno. La decadencia de la organización social es consecuencia del mal gobierno del monarca y de sus representantes pues en sus manos están los resortes para que la sociedad camine bien o mal.

\footnotetext{
${ }^{1}$ Cf.nota 1 donde citamos bibliografía.

${ }^{2}$ R.ARIE :L'Espagne musulmane.

${ }^{3}$ E.GARCIA GOMEZ y E.LEVI-PROVENÇAL: Sevilla a comienzos del siglo XII.,,Ob.cit.pág.20.

Ilbitem,págs.37-38
} 
Aunque no suelen existir en la mezquita mayor escuelas, sí que el cadí debía de instalar en las galerías a alfaquíes honrados que adoctrinaran a las gentes en las cuestiones religiosas,que les predicaran y les enseñasen lo que representaban las buenas obras entre ellas, la beneficiencia. Estos alfaquíes tendrían asignados ciertos estipendios y dinero a cargo de las herencias vacantes, donaciones, limosnas y otras obras pías de los creyentes,.. o bien se les asigna un salario. En esto están los inicios de que la enseñanza tuviera ciertas ayudas para los alfaquíes que dedicaban parte de su tiempo a la enseñanza de los niños. En las mezquitas se solía leer el Corán o las tradiciones de la Sunna,el resto de las ciencias y materias se estipuló que se leerían y enseñarían en las galerías o en las dependencias de los edificios ubicados junto al lugar sagrado,de aquí que muchas escuelas ocupen solares contiguos a las mezquitas.

A través de las noticias transmitidas por Ibn al-Jatib y otros cronistas y escritores nos encontramos cuestiones y notas sobre los estudios realizados por ciertos personajes relevantes de la cultura granadina.El cadí de la aljama tenía entre sus competencias la enseñanza, en ocasiones era sustituido en estos menesteres por sus ayudantes especialmente cuando éste tenía que desarrollar misiones diplomáticas u otros trabajos por encargo de la corte'. Uno de los maestros granadinos nacido en 1166 al finalizar sus clases repetía una oración dando gracias por lo estudiado aquel día "No hay poder ni fuerza sino en Allah, tesoro de los tesoros del paraíso.Allah nos depare cultura y se valga de nosotros según le satisfaga a $\mathrm{El}$ y a su Profeta y nos lleve a gozar de la otra vida".

La mención que nos transmite el Código de Yusuf I (13331354) reglamentando la vida religiosa,administrativa,militar y judicial del reino y de los súbditos nos hace ver la importancia que se le dió a la enseñanza,no pasó inadvertida sino que en primer

\footnotetext{
${ }^{1} \mathrm{M}^{\mathrm{a}}$ Isabel CALLRO SECALL: "El juez delegado de (Na'ib) del cadí en el reino nazarí de Granada", Andalucía Islámica.Texios y Estudios, IV-V (Granada,1986),pp.161-201.

${ }^{2}$ lbidem,pág.168.
} 
lugar se ordenaba que todos los pueblos establecerían escuelas gratuitas y uniformes en las enseñanzas. Esta ley y recomendación real nos permite constatar como el estado estaba profundamente preocupado por la enseñanza elemental en pleno siglo XIV. El reinado de Yusuf pudo hacer frente a muchas de estas cuestiones puesto que con este rey se inauguraba una etapa de paz,progreso y esplendor en Granada,consecuencia lógica de la liberación de problemas políticos y de poder contar con una economía saneada. Por tanto en el siglo XIV se ven signos claros de una intervención del estado en la enseñanza,al menos en la elemental.Se propugna una extensión de la misma entre todos los súbditos independientemente de sus recursos o del lugar donde vivieran.La consecuencia de toda esta planificación fue que comenzó una proliferación de intelectuales que lograron que Granada y sus comarcas se convirtieran en centros de primera línea dentro de la intelectualidad del mundo musulmán. No solo con Yusuf I sino con su hijo Muhammad V es cuando Granada,Guadix y otras ciudades alcanzan sus metas máximas en el estudio de las ciencias.

El propio Ibn al-Jatib es consciente de este papel director de la cultura, de la que fue un gran representante, y nos dice que Granada y sus alrededores tenían colegios, mezquitas, molinos y suntuosos edificios:

"Los lugares del radio de Granada ascienden a trescientos; los colegios y templos de su recinto son cincuenta, y los molinos de agua en torno a ella ciento treinta $^{\text {"1 }}$

Este esplendor granadino se mantuvo durante el siglo siguiente aunque más matizado pues en algunos escritos se entrevee el papel que en aquella sociedad jugaron los alfaquíes . En 1465 un viajero escribía que en la ciudad de Granada había abundantes congregaciones religiosas,que predominaba una floreciente cultura literaria, que sus oficios estaban regidos por hombres de elevada capacidad trabajadora y las técnicas eran excelentes, se lograban trabajos y obras maravillosas, en suma

\footnotetext{
' C.SANCHEZ ALBOORNOZ: La España musulmana. Ob.cit.,pág.S34.
} 
Granada según este autor era una de las grandes y más hermosas ciudades de Occidente ${ }^{1}$.

La ciudad estaba formada por un número considerable de barrios algunos de ellos de considerable extensión y en otros casos por exiguas manzanas de casas lo que suponía barriadas pequeñísimas.Si el barrio tenía población y superficie importante contaba con servicios públicos, cada harat tenía "baño, escuela, horno y alhondiga y una mezquita que tomaba el nombre del gremio y oficio más importante del barrio"2.

Creemos que no todos los centros religiosos tuvieron escuela pues de ser cierto esto se contabilizarían en los últimos tiempos de la Granada nazarí y primeros de los cristianos un total de 137 oratorios ${ }^{3}$. No tenemos referencias al número de mezquitas y oratorios de La Alhambra,aunque indudablemente el número sería elevado,se alude a mezquitas,escuelas,palacios reales y mansiones suntuosas. Esto nos lleva a pensar que el número total de centros religiosos era por tanto superior al que se puede obtener del estudio de los Libros de Habices .La distribución de estos centros religiosos es casi uniforme entre los barrios salvo en algunos de ellos como el de Nayd o el de al-Fajjarín dado que eran lugares apartados del centro de la capital y sobre todo con residencias acomodadas, jardines, cementerios, etc., y por tanto concentraban menor población que los otros barrios más céntricos.Así el Albaicín y otras zonas tenían un elevado índice de población.

El tamaño de las mezquitas, rábitas, gimas,...generalmente era pequeño y las noticias que poseemos nos indican que las superficies oscilaban entre los 6'25 y los 92'28 metros cuadrados

\footnotetext{
I'bidem, pág. 574 .

${ }^{2}$ L.SECO DE LUCENA: La Granada nazari del siglo XV.Granada,1975,pág.23.

$3 \mathrm{M}^{3}$ Teresa MARTINEZ PEREZ: "Las mezquitas de Granada en los Libros dc Habices",Andalucía Islámica.Textos y Estudios, IV-V,(Granada,1986),pp.203-235.

${ }^{4}$ L. SECO DE LUCENA: La Granada nazari.,,Ob.cit.,pág.17.
} 
siendo muy normal que las superficie media estuviera comprendida alrededor de los 60 metros cuadrados.Las medidas de estos inmuebles permiten hacerse una idea de la población que asistía al culto y la que generalmente habitaba el barrio ${ }^{2}$.

En los últimos años del dominio musulmán las escuelas debieron de abundar en la ciudad y en las poblaciones del reino.Las noticias que se obtienen del estudio de los Libros de Habices, publicados e inéditos ${ }^{2}$ nos permiten acercarnos al conocimiento de las escuelas, de sus dimensiones y posibilidades,lugar de ubicación dentro de los barrios,número de alumnos que podían asistir e ellas y el papel que ejercieron entre los servicios del barrio musulmán o de otros núcleos urbanos más pequeños ${ }^{3}$.

Dentro de la capital se describe en la parroquia de San Andrés una de las escuelas,situada sobre una tienda de los habices "Otra tienda devajo de la Escuela;está arrendada en mill e ochenta maravedis cada año"4. Este inmueble dedicado a la enseñanza en tiempos nazaríes permitió a los niños del barrio de Bab Ilbira aprender las primeras letras y nociones.Luis Seco de Lucena nos habla de todos estos barrios y de sus características

1 Sobre las mezquitas existe una abundante bibliografía,L.Torres Balbas,L.Seco de Lucena,M.Gómez Morcno y ot ros han estudiado esta cuestión en profundidad,ultimamente se puede ver M.ESPINAR MORENO y J.ABELLAN PEREZ: "Las rábitas en Andalucía.Fuentes y metodología para su estudio", I Congrès de les Ràpites de'l'Estat Espanyol "Els Ribats d'AlAndalus",Sant Carles de la Ràpita,1989,en prensa.

${ }^{2}$ Ma Carmen VILLANUEVA RICO: Habices de las mezquitas de la ciudad de Granada y sus alquerías. Edición,introducción e indices,por.. Madrid,1961. Ibidem, Casas, mezquitas y tiendas de los habices de las iglesias de Granada.Madrid,1966. Manuel ESPINAR MORENO: Esmuctura socioeconómica de las Alpujarras.Los Libros de Habices. Tesis Doctoral inédita,Granada,1980. Ibidem, Estructura económica de las iglesias alpujarreñas a través de los Libros de Habices. Granada,1981.M.ESPINAR MORENO y J.MARTINEZ RUIZ:Los Ogíjares.Estructura socioeconómica, toponimia, onomástica, según el Libro de Habicesde (1547-1548). Granada,1983Jbidem, Ugújar según los libros de Habices. Granada,1983.Además el prof. Espinar ha publicado varios trabajos sobre las alquerías granadinas de Dílar,Gójar,Churriana,Otura,Gabia la Grande,etc.,basándose en la documentación de habices.

\footnotetext{
${ }^{3}$ M. ESPINAR MORENO:"Dei urbanismo musulmán al urbanismo cristiano..",Ob.cit.
}

${ }^{4} \mathrm{M}^{\mathrm{a}}$ Carmen VILlANUEVA: Habices de las mezquilas.., Ob.cit.,pág. 80. 
peculiares $^{1}$,respecto a este nos recuerda "Sabemos de dos escuelas musulmanas que hubo en este núcleo urbano:una muy cerca de Bab Ilbira;y otra junto a la mezquita donde hoy se encuentra San Andrés"'. En la colación de San Andrés existieron 13 centros religiosos ${ }^{3}$.

Cerca de la anterior,en la Puerta de Elvira, se nos cita otra escuela que en tiempos cristianos estaba arrendada a Alonso Venegas Abdulazis, a Albarrazín y a Francisco Zayen, en este arrendamiento entreba una haza ubicada cerca de la Puerta Elvira ".. en conpañía del escuela de Vin Alvira,arrendada en mill e setezientos e sesenta e ocho maravedis, lo que le perteneze" ${ }^{n-4}$ Es curioso constatar como algunos de los bienes de habices estaban asignados a sufragar los gastos de la enseñanza.El barrio de Bab Ilbira contaba por tanto con dos escuelas, a una de ellas se refiere Gomez Moreno en su Guía de Granadas.

Cerca de Santa Ana, antigua gima Almanzora, nos encontranmos otra tienda arrendada en 672 maravedíes al año que estaba junto a otra escuela,ésta quedaba ubicada en una de las vías de comunicación que unía ambas márgenes del Darro "Una tienda en la Puente de Santa Ana,debajo del escuela morisca,en que está Garzía Allazaraque". . En este barrio musulmán se localizaban 5 centros religiosos ${ }^{7}$. Era el famoso barrio de alMansura que se remonta al siglo XI con los ziríes y especialmente al monarca Badis ben Habbus, barrio que se dedicó a este monarca por sus acciones guerreras,algunos de los edificios fueron

\footnotetext{
' L.SECO DE LUCINNA: La Granada nazari.., Ob.cit,pág.50 y ss.

2 Ibidem, pág. 50 .

${ }^{3} \mathrm{M}^{\mathrm{a}}$ Teresa MARTINEZ PEREZ; "Las mezquitas de Granada., "Ob.cit.,pp.205-207.

${ }^{4} \mathrm{M}^{3}$ Carmen VILI ANUEVA: Habices de las mezquitas.., Ob.cit.,pág.83

5 M.GOMEZ MORENO: Guia de Granada.Granada,1892,pág.381.

${ }^{6} \mathrm{M}^{3}$ Carmen VILIANUEVA: Habices de las mezquitas., Ob.cit.,pág.130.

${ }^{7} \mathrm{M}^{\mathrm{a}}$ Teresa MARTINEZ:"Las mezquitas de Granada..",Ob.cit.,pp.204-205.
} 
financiados igual que las mezquitas por personajes de renombre en aquellos tiempos,así se describen las obras del puente del cadí Ibn Tawba,junto al puente se describe una mahdara o escuela, Luis Seco de Lucena nos recuerda también la importancia de la mezquita de Ibn Tawba'.

Otra de las escuelas primarias de aquellos tiempos se ubicaba en la Plaza de la Gran Mezquita - rahbat Masyid alAzam - y cerca de la aljama estaba este colegio o escuela primaria (mahdara) y la casa del Lavatorio o Dar al-Wadu2. Un documento publicado por Gaspar y Remiro ${ }^{3}$ citaba la palabra alhadara, en lugat de al-mahdara, error que más: tarde fue corregido, así lo expresan Gomez Moreno Y Torres Balbas ${ }^{4}$.Nos dicen que mahdara significa "escuela donde se aprende a leer" ${ }^{\prime \prime}$,siguiendo a Dozy y a Pedro de Alcalá.

En los Libros de Habices se cita esta escuela primaria y la Madraza o centro superior con residencia para los estudiantes "a la manera de nuestros colegios mayores":Se cita una tienda junto con las casas de los estudiantes ${ }^{7}$.Al lado de la escuela se describe este inmueble ".. otra tienda, junto con la escuela, esta vazía","Otra tienda linde de la dicha escuela, en que solía estar el

\footnotetext{
${ }^{1}$ L.SECO DE LUCENA: La Granada nazarí.,Ob.cit,.pág.86.

${ }^{2}$ L.SECO DE LUCENA: La Granada nazarí., Ob.cit.,pp.65-66, nota 2. L.TORRES BALBAS,"La mezquita mayor de Granada",Al-Andalus, X(1945),pp.409-432.M.GOMEZ MORENO: Monumentos arquitectónicos de España, pág.51,núm.1.

${ }^{3}$ Mariano GASPAR Y REMIRO: Escrituras árabes granadinas,pp.13-16.

${ }^{4}$ M.GOMEZ MORENO: Guía de Granada. Ob.cit.,Jbidem,Monumentos arquitectónicos.., Ob.cit., L.TORRES BALBAS, "La mezquita mayor..",Ob.cit.

s Ibidem,además L.SECO DE LUCENA: La Granada nazarí., Ob.cit.

${ }^{6}$ L.SECO DE LUCENA cita testimonios de estos autores en La Granada nazari.,ob.cit.

${ }^{7}$ L.SECODE LUCENA: La Granada nazari..,Ob.cit.,M² del Carmen VILLANUEVA: Habices de las mezquitas..,Ob.cit.,pág.27.

${ }^{8} \mathbf{M}^{2}$ del Carmen VILLANUEVA: Habices de las mezquitas.., pág.28.
} 
Cadí"'. Como se puede ver el cadí ocupaba un lugar privilegiado dentro del barrio y cerca de los lugares de enseñanza y de la mezquita aljama.La importancia del lugar dentro de la capital es descrita de esta forma por Seco de Lucena "Esta plaza fue el centro vital de la Granada musulmana.En sus inmediaciones se hallaba la Alcaicería y los más importantes zocos de la medina.Entre la Gran Mezquita y la mahdara antes citada, poco más o menos donde está la puerta que ahora da acceso a la Capilla Real, se abría la sinuosa calle de Sawtar que siguiendo dirección N, conducía al darb Abi-l- Asi o adarve urbano curioso de Abu-l- Asi, barrio aristocrático aislado de los vecinos"'.

En el barrio del Mawror en lo mas elevado del barrio había otra mahdara o escuela,una fuente que abastecía de agua a los vecinos y un horno ${ }^{3}$. Por tanto cerca de Torres Bermejas se describe "Un establo con una camara enzima, linde del escuela morisca e de casa del Alcaide de Guedix.Vendiolo el Pequeñín ${ }^{\prime \prime}$.

Cerca de la mezquita que luego se dedicó a la advocación de San Miguel y que se conoció como San Miguel Bajo, existió otra escuela primaria y un baño.La renta de un horno situado detras de una tienda pertenecía a los habices,a la renta de la hagüela y a otras instituciones de época musulmana,se nos dice que " Un horno a las espaldas de la dicha tienda,es de ciertos habizes,tiene en el Haguela un pesante e medio cada luna,e de lo que más rendiere el quarto el algibe, e lo restante se reparte: la mitad para San Miguel e la otra mitad para una escuela, que biene a la dicha Iglesia de sant miguel, segund por lo que está arrendado, setecientos e cinquenta maravedís". La escuela por tanto estaba en ocasiones financiada por los bienes que producía el horno.Así tenemos que muchas de estas escuelas se pagaban y

\footnotetext{
isidem,pág.29,nota 1.

${ }^{2}$ L.SECO DE LUCENA: La Granada nazarí., Ob.cit..pág.67.

${ }^{3}$ Ibidem, pág. 88.

${ }^{4} \mathrm{M}^{\mathrm{a}}$ del Carmen VIllaNUEVA: Habices de las mezquitas..., Ob.cit.,pág.138.

${ }^{5} \mathrm{M}^{3}$ del Carmen VILlaNUEVA: Habices de las mezquitas.,, Ob.cit.,pág.151.
} 


\section{ESCUELAS Y ENSEÑANZA PRIMARLA EN LA ESPAÑA MUSULMANA.}

financiaban con el dinero de las rentas de tiendas, hornos, aljibes, tierras, árboles,etc., o bien de limosnas de los creyentes que en ocasiones eran donaciones a perpetuidad, lo que nos indica la preocupación social por la enseñanza entre los musulmanes granadinos.

En la colación de San Nicolás, enfrente de la mezquita denominada Masda ibn Da mun, se describe otra escuela primaria o mahdara cuyas dimensiones eran de $7 ' 5 \times 3$ varas $^{1}$, ocupaba una superficie aproximada de 15'67 metros cuadrados.Cerca de ella había un horno.La descripción del inmueble nos permite ver la importancia que tenía esta:

"Visitose Una Cámara que en Tienpo de moros solía ser escuela de Vezar leer a moros, lindava con cassa de Juan audelhac y de la otra parte con un establo del dicho Juan bue año,Correro, tenía dicha Cámara a Zenso Juan / Abenozarre por 300 maravedís al año perpetuamente,y también entrava en dicho prezio la Rávita de Mazi Abendamón que estava enfrente de esta Cámara que la tenía a censo él dicho Abenozarre tío de Junco, estava zerrada dicha cámara; midiose por defuera y tubo de largo la entrada dos varas y media y de ancho tres varas, la Cámara tubo de largo siete varas y media por que estava sobre un establo del dicho Juan Buenaño, y de ancho tubo tres varas"

En San Juan de los Reyes o Masyid al-Taibin (mezquita de los Conversos) que era el centro del famoso barrio de Ajsaris existieron varias mezquitas, baños, hornos, el Maristan u hospital y otros edificios. Muy cerca del actual templo nos encontramos la existencia en época musulmana de otra mahdara o escuela situada en una pequeña placeta que da vista a la fachada principal del templo de San Juan de los Reyes ${ }^{3}$. Por allí pasaba la acequia de Ajsaris o saqiyat Ajsaris que surtía de agua al barrio y continuaba hacia otras partes de la ciudad.Entre los testimonios de los habices se nos describe el inmueble que había servido de escuela en

\footnotetext{
'La vara equivale a 0'836 mis.Cf.L.SECO DE LUCENA: La Granada nazari.,Ob.cit.

${ }^{2} \mathrm{M}^{2}$ del Carmen VILLANUEVA: Casas,mezquitas y tiendas..,Ob.cit.,pág.103.

${ }^{3}$ L.SECO DE LUCENA: La Granada nazarí.,Ob.cit.,pág.130
} 
tiempos de los musulmanes:

"Visitose un alhorí, que solía ser escuela de bezar Mochachos, y lo incorporó en las Cassas de su morada Doña Ysabel, muger de Don Andrés el Baztí, frente de la puerta principal de San Juan de los Reyes, de cuia Iglesia lo tenía a Censo por 118 maravedís al año perpetuamente $=$ dize al margen con letra antigua $=$ Tiénela Doña Ana Bastia, hixa de esta Doña Ysabel, paga quatro Reales y un quartillo"1.

Gima o Sami al- Burriyani estuvo cerca de San Bartolomé,lindando con el barrio de Saria y el primitivo recinto del Albaicíñ.

La mezquita del Albaicín luego consagrada iglesia por Cisneros en 1499 y dedicada como parroquia del Salvador en 1501 tenía una plazoleta a su lado de la que se desconoce el nombre aunque la citan Gomez Moreno y Seco de Lucena ${ }^{3}$, y más tarde denominada por los cristianos placeta o plaza del Salvador. Enfrente de la mezquita se instaló en época musulmana otra escuela primaria o mahdara y una alhondiga. En la relación de bienes habices nos encontramos una casa y tienda con un almacén junto a la tienda "linde del escuela" y de la tienda de San Salvador ${ }^{4}$, además otra tienda también era lindera con este pequeño colegio.

En el pequeño barrio de al-Aywaz (la pareja) 0 de Rabadalgeos donde hoy está la ermita de San Miguel, sobre la rawda, aunque no sabemos el nombre exacto de esta mezquita o rábita,se conoce la existencia de otra escuela o mahdara y una

\footnotetext{
${ }^{1} \mathrm{M}^{\mathrm{3}}$ del Carmen VILLANUEVA: Casas,mezquitas y tiendas.., Ob.cit.,pág.59.

${ }^{2}$ Cf. SECO DE LUCENA: La Granada nazari.., MARTTNEZ PEREZ,"Las mezquitas de Granada..".

${ }^{3}$ M.GOMEZ MORENO:"Granada en el siglo XIII",Cuadernos de La Alhambra, 2(1966).L.SECO DE LUCENA:La Granada nazarí.,pág.146.

${ }^{4} \mathrm{M}^{2}$ del Carmen VILlaNUEVA: Habices de las mezquitas.,, Ob.cit.,pág.164.
} 
alhondiga,separadas por una atarbea ${ }^{1}$. Por tanto el inmueble destinado a la enseñanza es descrito de la siguiente manera "Una tarabea en Rabadalhageos, linde el escuela e el alhondiga; está vacía: suele rentar setecientos e veinte maravedís cada año"2.

La aljama de Majadalfezi o Majadat al-Fasi (el Vado del Feci o el de Fez) posiblemente asiento de la primera iglesia de San Justo y Pastor que estuvo adosada al convento de la Encarnación,cuestión que no está muy clara para los estudiosos de los centros religiosos ya que no existen datos que indiquen esto ${ }^{3}$. Por el contrario bien pudo ser otra mezquita denominada Zacaia Talbazeri o Saqayat al-Bazzarin.Cerca de este centro religioso musulmán se ubicaba otra de las escuelas aunque desconocemos su emplazamiento exacto si conocemos:algo de sus rentas y financiación "Una tienda alinde del algibe, que es el tercio de la dicha xima de Zacaia Talbezeri, e el otro tercio de la escuela, e el otro tercio del algibe, está arrendada en trezientos e sesenta maravedís cada año"it.

En San Pedro se describe otra tienda lindera de la algima y de la escuela,por tanto se localiza otra de las mahdaras dentro de Granada,con ello se enriquece el conocimiento de los centros de enseñanza en las distintas zonas y barrios granadinos.

No se les olvida a los conocedores de los bienes habices citar otra escuela en San Luis,especificando las medidas alcanzadas por este edificio destinado a la enseñanza y mas tarde fue ocupado y destinado a otros menesteres,así es descrito por los deslindadores:

"Vissitose una Rávita bajo de la Yglesia de San Luis, frente a una Calleja que solía ser escucla donde bezaban mochachos, corría por arrendamiento,

\footnotetext{
${ }^{1}$ L.SECO DE LUCENA: La Granada nazarí.,Ob.cit.,pág.150.

${ }^{2} \mathrm{M}^{\mathrm{a}}$ del Carmen VILLANUEVA: Habices de Las mezquitas., Ob.cit.,pág.165.

${ }^{3} \mathrm{M}^{2}$ Teresa MARTINEZ PEREZ: "Las mezquitas de Granada..",Ob.cit.

${ }^{4} \mathrm{M}^{2}$ del Carmen VILlANUEVA: Habices de las mezquitas.,, Ob.cit.,pág.147.
} 
lindaba con casa de ... y con la calle de San Luis, la qual dicha Rábita hera un alto;tubo de largo siete baras y de ancho por la parte de la puerta dos baras, y por la otra parte tres baras, y el aire de esta Rábita era suyo"

\section{OTROS CENTROS DE ENSEÑANZA.}

Además de las escuelas situadas en el interior de la capital se constatan otras en la Alpujarra,Vega de Granada,Guadix,Baza y otros lugares del reino nazarí. El propio Ibn al-Jatib nos cita la existencia de una escuela alcoránica en la ciudad de Baza donde estudió Alí ben Umar ben Ibrahin ben Abdalla al-Kinani al Qiyati Abu-l-Hasan,allí aprendió el Corán y otras disciplinas trasladándose más tarde a Granada para completar sus estudios.Este afamado maestro del polígrafo granadino cuando acababa las clases daba gracias a Dios,tesoro de los tesoros del Paraíso, implorando que concediera a los hombres cultura para hacer frente a los problemas de esta vida y prepararnos para la futura $^{2}$. Este insigne maestro había nacido en $1252^{3}$. El ministro granadino tras estudiar en una escuela primaria de Loja se trasladó a Granada y aquí pasó a ser discípulo del maestro bastetano del que aprendió literatura coránica, fiqh, lengua y adab.

Conocemos la existencia de otros de estos colegios en la ciudad de Guadix, gracias a documentos castellanos de 28 de julio de 1491, tras la conquista de la ciudad,los Reyes Católicos concedieron bienes a las iglesias.Entre los inmuebles donados nos encontramos que se hace referencia a las escuelas de las parroquias de San Pedro, San Miguel y de la Iglesia Mayor o Catedral.Estos bienes fueron más tarde ratificados en 1493 y en fechas posteriores ${ }^{4}$.La escuela donada a la Iglesia Mayor se encontraba sobre uno de los aljibes del agua que surtía a la anterior Mezquita Mayor.Las rentas de esta escuela fueron

\footnotetext{
I Ibidem, Casas,mezquitas y tiendas.,.,Ob.cit.,pág.112.

${ }^{2} \mathrm{M}^{2}$ Isabel CALERO SECALL:"EI juez delegado..",Ob.cit.,pág.165.

3 Ibidem.

4 M.ESPINAR MORENO Y OTROS: "La Iglesia en la repoblación de Guadix(Siglo XV).Dotación de los Reyes Católicos",Actas del I Coloquio de Historia.Guadix,1989,pp.103-114.
} 
repartidas la mitad para la fábrica de la Iglesia y la otra mitad para el obispo ${ }^{1}$. Algunas noticias apuntan a la existencia de escuelas en las tierras del Cenete ${ }^{2}$.

En la Vega de Granada el Libro de Habices de 1547-1548 nos cita que en la alquería de Gójar había una escuela primaria o mahdara que se financiaba en parte con la renta que producía una de las hazas de los habices. Otros documentos de habices nos recuerdan al respecto sobre este colegio:

"Otra media haza en compañía de otra media del escuela del dicha alcaría, en el dicho pago; linderos con una haza de Lebque e con una viña" ${ }^{4+}$.

La alquería de Dílar tenía otra escuela en el barrio de Alfondón convertida en solar's. Muchos de estos inmuebles al dejar de cumplir su misión fueron aprovechados por los repobladores o por los moriscos arrendatarios de estos bienes y destinados a otros menesteres.La escuela de Dílar es descrita en el Libro de Habices de 1547-1548 de la siguiente manera:

"Un solar de capilla donde abezavan a leer mochachos en tienpo de moros, el qual se midió e tovo en largo diez e siete pies y en ancho treze pies, que

\footnotetext{
Itidem.

${ }^{2} M^{2}$ del Carmen VILLANUEVA:"Un curioso pleito de los Habices del Marquesado del Cenete",Miscelánea de Estudios dedicados al prof.A.Marín Ocete,Granada,1974,Tomo II,pp.1154 y ss. J.ALBARRACIN Y OTROS: El Marquesado del Cenete.Hístoria, Toponimia y Onomástica según documentos árabes inéditos.Granada,1986,2 vols. y M.GOMEZ LORENTE:"Bienes Habices del Marquesado del Cenete a principios del siglo XVI ${ }^{n}$ Actas del I Coloquio de Historia, Guadix,1989,pp.61-68.

${ }^{3} \mathrm{M}^{\mathrm{a}}$ del Carmen VILLANUEVA: Habices de las mezquitas., Ob.cit.y Manuel ESPINAR MORENO,"Noticias para el estudio de la alquería de Gójar.Bienes Habices",Cuadernos de Estudios Medievales, X-XI (Granada,1983),pp.105-148.

${ }^{4} \mathbf{M}^{2}$ del Carmen VILLANUEVA: Habices de las mezquizas., Ob.cit.,pág.279.

5M.ESPINAR MORENO, "Apeo y deslinde de los habices de Dilar (1547)",M.E.A.H.,XXIXXXX (Granada,1980-1981),pp.135-161.
} 
alinda con casas de Diego Monayn e el barranco y con las calles Reales"'.

La superficie de este inmueble nos indica que podían asistir a ella un número importante de niños de aquel barrio de Dílar.

Testimonios parecidos existen en las alquerías de Albolote y de Alfacar.En la primera de ellas existe una descripción muy interesante sobre el destino de una pequeña torre convertida en carnicería que es como sigue:

"Una torrecilla ques carnicería de Albolote, que era çuma de tiempo de moros, ques de la yglesia de Albolote, questa junto al barranco del alquería e frontero del Añora del agua, tiénela a çenso Juan de Salamanca, a de mostrar título dello"'?

La otra escuela estaba en el lugar de Alfacar,en la denominada alquería Baja, y en el momento del apeo y deslinde de los habices estaba convertida en corral de una de las casas del lugar.El testimonio de los apeadores dice lo siguiente:

"Un corralico donde enseñavan en tienpo de moros a los niños, que es de diez pies en largo e ocho en ancho, que alinda con casas del Zarbal e con casas de Fernando Nabil e con la calle, ase de dar a çenso"".

En la Alpujarra encontramos también noticias sobre escuelas musulmanas, así en el.año 1500 los Reyes Católicos premian al alfaquí alpujarreño Hernando Abenedeuz por su conversión al cristianismo entregándole los bienes habices de una de las rábitas situadas en Laujar de Andarax. ${ }^{4}$. El 30 de agosto

\footnotetext{
I Ibidem.Además libro de Habices de 1547-1548 conservado en el Archivo de la Curia Eclesiástica de Granada,fol.12r.Estos materiales han sido transcritos y preparamos su edición.

${ }^{2}$ Ibidem, fol.120r.

${ }^{3}$ Ibidem, fol.144r.

4 Manuel ESPINAR MORENO: "Hernando Abenedeuz.Un alfaquí alpujarreño (1500)",Awraq, IV (Madrid,1981),pp.185-189.
} 
conceden aquella merced como salario y mantenimiento de este personaje "que soliades llevar por alfaquí con que podays aprender las cosas de nuestra Sancta Fee catolica e podays tener con que vos sustentar e mantener"1

Entre los bienes urbanos concedidos nos aparecen un horno,casa,solar de rábita y una escuela,todo ubicado en el Zoco del Laujar de Andarax. la escuela alcanzaba unas dimensiones de $14 \times 11$ pies lo que equivale a una superficie de 11'98 metros cuadrados.La cesión de estos inmuebles nos recuerda como entre las funciones de los alfaquíes estaba la de enseñar a los niños pequeños, cuidar los edificios y procurar que los pequeños conocieran al menos unas nociones elementales.El documento se conserva en el Libro de Habices de 1530 y nos dice que en esta escuela era donde se enseñaba a los habitantes de aquel lugar "do enseñaban a leher los mochachos en tienpo de moros"2.

I Ibidem, pág.189.

${ }^{2}$ Ibidem. 